\title{
Do laboratory challenge tests for occupational asthma represent what happens in the workplace?
}

\author{
P. Sherwood Burge, Vicky C. Moore, Alastair S. Robertson and Gareth I. Walters \\ Affiliation: \\ Occupational Lung Disease Unit, Birmingham Heartlands Hospital, Birmingham, UK. \\ Correspondence: \\ P. Sherwood Burge, Occupational Lung Disease Unit, Birmingham Heartlands Hospital, Birmingham B9 5SS, UK. \\ E-mail: sherwood.burgedheartofengland.nhs.uk
}

@ERSpublications

Positive specific challenge tests with occupational agents in the laboratory and real-life work exposures monitored with PEF show similar reactions

http://ow.ly/lNuv30jWDtQ

Cite this article as: Burge PS, Moore VC, Robertson AS, et al. Do laboratory challenge tests for occupational asthma represent what happens in the workplace? Eur Respir J 2018; 51: 1800059 [https://doi. org/10.1183/13993003.00059-2018].

ABSTRACT Specific inhalation challenge (SIC) is the diagnostic reference standard for occupational asthma; however, a positive test cannot be considered truly significant unless it can be reproduced by usual work exposures. We have compared the timing and responses during SIC in hospital to Oasys analysis of serial peak expiratory flow (PEF) during usual work exposures.

All workers with a positive SIC to occupational agents between 2006 and 2015 were asked to measure PEF every $2 \mathrm{~h}$ from waking to sleeping for 4 weeks during usual occupational exposures. Responses were compared between the laboratory challenge and the real-world exposures at work.

All 53 workers with positive SIC were included. 49 out of 53 had records suitable for Oasys analysis, 14 required more than one attempt and all confirmed occupational work-related changes in PEF. Immediate SIC reactors and deterioration within the first $2 \mathrm{~h}$ of starting work were significantly correlated with early recovery, and late SIC reactors and a delayed start to workplace deterioration were significantly correlated with delayed recovery. Dual SIC reactions had features of immediate or late SIC reactions at work rather than dual reactions.

The concordance of timings of reactions during SIC and at work provides further validation for the clinical significance of each test. 


\section{Introduction}

Specific inhalation challenge (SIC) is the reference standard for the diagnosis of occupational asthma [1]. Some centres use this as the primary method of diagnosing occupational asthma, whereas others (including our hospital) restrict its use to workers for whom the cause of their occupational asthma is unclear and where finding a specific cause may alter management of the individual worker or the workplace. Instead, we use the analysis of serial measurements of peak expiratory flow (PEF) at home and at work as our primary method of validating a history of occupational asthma. We diagnose occupational asthma when this is the most likely clinical diagnosis based on all the evidence available. If the worker is still exposed at work, we expect to find a positive Oasys analysis of serial peak flow records at home and work [2-4]; if the worker is relocated away from exposure in the original workplace, our investigation would include either a workplace or laboratory challenge; if the worker has left work, SIC would only be done if the worker's future employment depended on the result (e.g. an orthopaedic anaesthetist with possible acrylate sensitivity). In our clinic, $85 \%$ of instances of occupational asthma are confirmed using objective tests [5]. The remaining $15 \%$ are diagnosed from a history of work-related asthma and exposure to an asthmogen, but without objective confirmation. In these cases, the worker is no longer being exposed to the asthmogen by the time we see them, so the recording of serial PEF measurements with exposure is not possible. Compensation for occupational asthma in the UK is not decided by clinicians and does not necessarily require objective confirmation; it is instead based on "the balance of probabilities", i.e. occupational exposure is the most likely cause of the asthma. Many patients are not compensated because of a lack of sufficient disability from asthma when away from work.

The patterns of response to single exposures in the laboratory have been established as immediate (starting within minutes of exposure and resolving within $2 \mathrm{~h}$ ), late (starting more than $1 \mathrm{~h}$ after exposure and usually lasting several hours), dual (an immediate reaction with resolution before a subsequent late reaction) or prolonged immediate (when there is little recovery between immediate and late components) [6]. There are some additional variants, particularly recurrent reactions for several days after a single exposure [7]. Other methods of validating the diagnosis of occupational asthma include measuring nonspecific bronchial reactivity (NSBR) at and away from exposure and finding specific $\operatorname{IgE}$ to occupational agents. Both have sensitivity and specificity significantly below that achieved with serial PEF measurements [8].

Exposures in the laboratory are usually of short duration, from a few breaths up to $120 \mathrm{~min}$, and are terminated if a significant immediate reaction occurs. In the workplace, exposure continues for the whole shift and reactions are superimposed onto the normal diurnal variation in airway calibre, with the nadir shortly before waking and the maximum usually 6-12 h later [9-11].

The patterns of response to usual exposures in the workplace have been classified depending on the speed of the start of the reaction, the rate of recovery and the shift worked [12-14]. The patterns within a day at work have immediate and delayed onsets, similar to the timings seen in SIC, but they also have a "flat" pattern, in which the PEF fails to increase during the day as seen on days away from work, without a subsequent fall after the onset of work exposure. Successive daily exposure often leads to progressively worse asthma as the week progresses, particularly when recovery is incomplete before the next day's exposure.

There are no previous reports of the relationship between the timings of response during SIC testing and real-world responses to exposures at work. The aims of this study were to compare the results of positive SIC exposures in hospital with the response to real-world exposures in the workplace, and to investigate how the timing of asthmatic reaction during SIC testing in the laboratory relates to the timings of response to the same agents in the workplace in sensitised workers. We postulated that those with an immediate SIC reaction would start to react within $1 \mathrm{~h}$ of regular occupational exposure and start to recover within $1 \mathrm{~h}$ of leaving work, whereas those with a late reaction would have delayed response and delayed recovery. Those with dual or prolonged immediate reactions would show early deterioration and delayed recovery.

\section{Methods}

Between 2006 and 2015 our unit diagnosed 343 workers with occupational asthma with latency (suggesting a hypersensitivity mechanism). 111 workers had specific challenge tests as inpatients, including some in whom occupational asthma was excluded. The 53 workers with positive tests form the cohort for this study. Testing was mostly by realistic exposure, including tipping powders, such as offset sprays and baking ingredients; painting liquids such as paints, volatile isocyanates and cleaning agents; heating soldering fluxes and methylene diisocyanate; and nebulising substances normally nebulised at work, such as metalworking fluids and contaminated aqueous aerosols. Metals were tested by nebulising soluble salts, potassium dichromate, cobalt chloride, zinc sulfate and aluminium chloride (table 1). Workers wore 
TABLE 1 Agents with positive specific challenges by type of reaction (immediate, late, dual/ prolonged immediate)

\begin{tabular}{|c|c|c|c|}
\hline \multirow[t]{2}{*}{ Agent } & \multicolumn{3}{|c|}{ Specific inhalation challenge reaction } \\
\hline & Immediate & Late & Dual \\
\hline Offset printing sprays containing maize & & 1 & 1 \\
\hline Baking ingredients (nuts and improvers) & 2 & & \\
\hline Contaminated aqueous aerosols & & 2 & \\
\hline Isocyanates & 3 & 4 & 4 \\
\hline Epoxy resin amines & 2 & & 1 \\
\hline Acrylates & & & 1 \\
\hline Polyester & & & 1 \\
\hline Non-colophony soldering fluxes & 1 & & 2 \\
\hline Wood, medium density fibreboard (MDF) & 1 & & \\
\hline Used metalworking fluids & 2 & 1 & 2 \\
\hline Chrome & 2 & & 5 \\
\hline Cobalt & 1 & 1 & \\
\hline Zinc & 2 & & \\
\hline Aluminium & & & 1 \\
\hline Cleaning products & 2 & & 3 \\
\hline Biocides & & & 2 \\
\hline Chloramines & & & 1 \\
\hline Fragrance (cherry) & 1 & & \\
\hline Lime and sand & 1 & & \\
\hline
\end{tabular}

protective clothing to prevent skin and eye absorption. All had control exposures on separate days, mostly with materials to which they were also exposed at work, e.g. unused metalworking fluid, other metals or soldering fluxes. Reactions during SIC were classified as immediate, late or dual. Immediate reactions were those with $\mathrm{a} \geqslant 15 \%$ fall in forced expiratory volume in $1 \mathrm{~s}$ (FEV1) within the first hour compared to a control exposure (figure 1a); late reactions were determined by a delayed reaction of $>1 \mathrm{~h}$ followed by either a $\geqslant 15 \%$ fall in FEV1 [1] or two measurements below the lower limit of normal calculated from three control days using the pooled standard deviation method of STENTON et al. [15] (figure 2a); dual reactions had both immediate and late components. In five workers there was a $>15 \%$ fall in FEV1 in either the immediate or late component of the reaction, and a consistent $11-15 \%$ fall in the other component: these were also classified as dual reactions.

All participants were asked to carry out serial PEF records approximately every $2 \mathrm{~h}$ from waking to sleeping for 4 weeks on days at and away from work before the SIC. Most used data-logging meters recording the best of three blows and the time. The meters used changed over time and included the Mini Wright digital and e-mini Wright (Clement Clarke, Harlow, UK) and Piko-1 from Ferraris (Hertford, UK) or Nspire (Hertford, UK), with some recordings made using manual Mini Wright meters. The mean hourly PEF from waking to sleeping was calculated separately for days at and away from work using the area between curves $(\mathrm{ABC})$ analysis from the Oasys plotter [3]; this requires at least 3 days with measurements within $2 \mathrm{~h}$ of each other on days at and away from work to calculate the mean hourly PEF for a specific time. To identify the timing for a start of deterioration at work or recovery away from work, a minimum of 3 days with readings in the 2-h time block after starting and after stopping work was required. If the record was inadequate the worker was asked to repeat it. If waking time was equivalent on work and rest days, the time-point analysis (using the same pooled standard deviation method) was added to the plot [4]. If there was more than one type of work exposure during the record, these were plotted separately. Oasys also calculates the mean PEF on each consecutive "day" at and away from work. "Days" begin with the first measurement after the start of work and finish on the last measurement before work on the next day. The plot was assessed to see if successive workdays resulted in equivalent or progressive deterioration, and whether improvement away from work was maximal on the first day away from work, or took longer (figures $1 \mathrm{~b}$ and $2 \mathrm{~b}$ ).

Four experts independently scored the ABC plots to identify workplace deterioration beginning at the first time-point after the start of work (figure 1c) or $>2 \mathrm{~h}$ later (delayed deterioration, figure $2 \mathrm{c}$ ), and starting to recover at the first time-point after leaving work (figure 1c) or $>2 \mathrm{~h}$ later (figure $2 \mathrm{c}$ ). "Flat" reactions were identified when there was a significant difference in PEF between days at and away from work, but there was no fall in PEF after starting work; these were included with immediate reactions if the first difference 


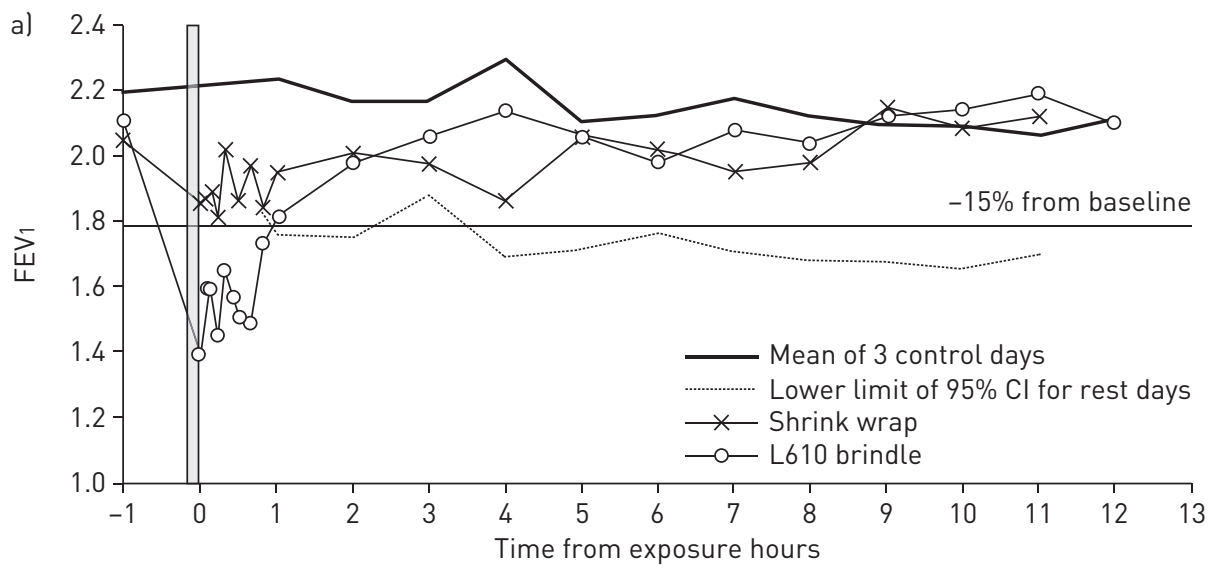

b)
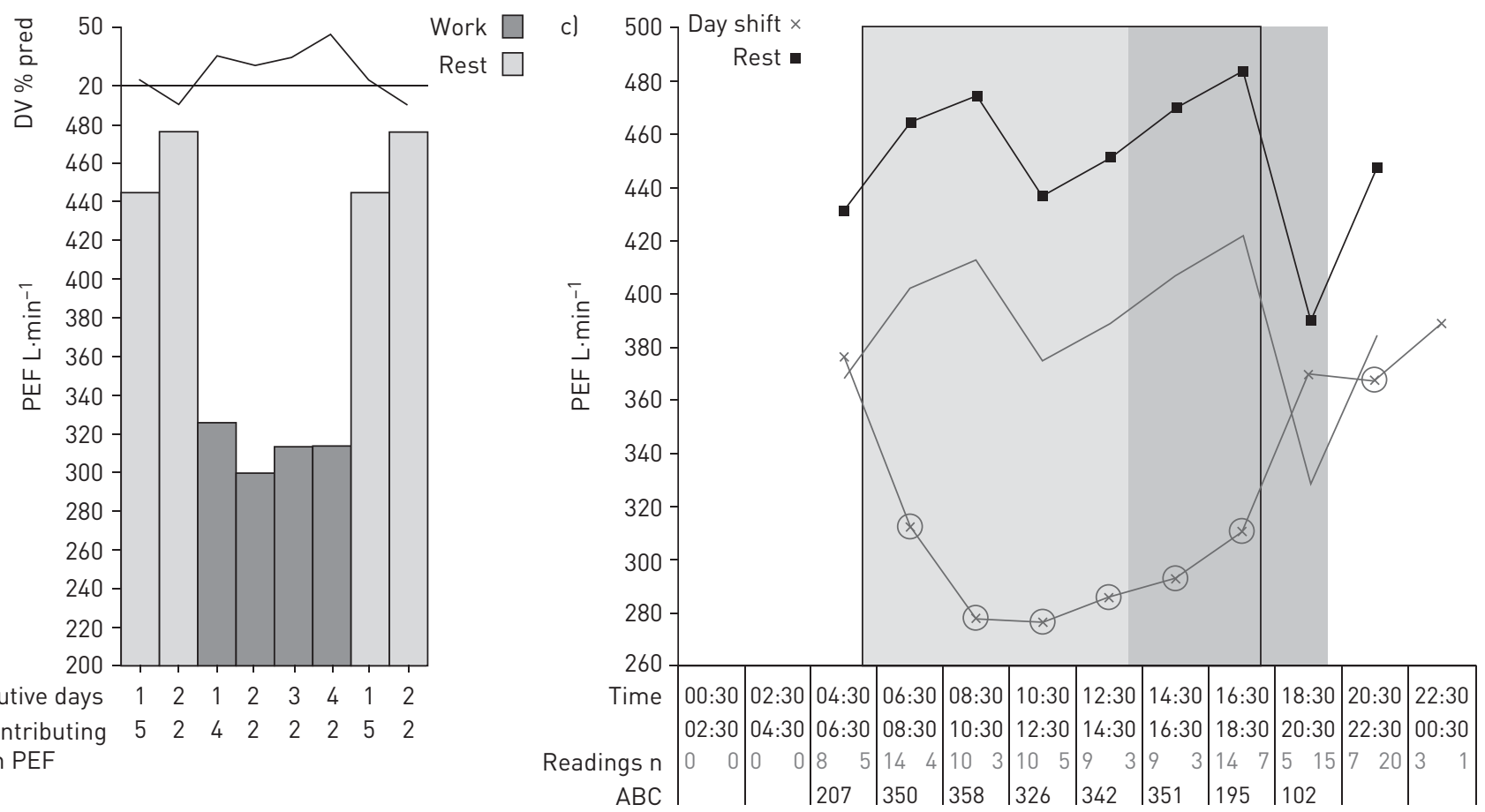

FIGURE 1 Data from a maintenance fitter in a roof tile-manufacturing factory. a) Specific inhalation test shows the mean hourly peak expiratory flow (PEF) during three rest days away from exposure immediately preceding the challenge tests, the pooled lower limit of the $95 \% \mathrm{Cl}$ for these readings, and responses to two specific challenges on separate days. There was no significant reaction to heating of the shrink-wrap plastic used to pack the tiles at work, but a significant immediate reaction following exposure to the nebulised chromate pigment (L610 brindle) used to spray the tiles. There was no late component to this reaction. b) Mean PEF on successive days away from exposure and successive days at work. The top panel shows the mean diurnal variation (DV) for each day as a percentage of the predicted value. The main panel shows the mean PEF for each successive control or work day. The top row of the bottom panel numbers the first and second consecutive control days away from work either side of days 1-4 at work. The bottom row of the bottom panel indicates the number of days contributing to each mean daily PEF. The plot shows equivalent deterioration on each successive workday and that recovery is better on the second day away from work. c) Mean 2-hourly PEF control days away from work (with $95 \% \mathrm{Cl}$ parallel below) and workdays. Grey background indicates periods at work. Vertical lines indicate the modal times of starting work $(06: 00 \mathrm{~h})$ and stopping work $(18: 00 \mathrm{~h})$. Dark grey indicates the earliest time of leaving work (14:00 h) and latest time for leaving work $(20: 00 \mathrm{~h})$. The first two lines in the bottom panel show the times in 2-hourly blocks; below this are the number of days with readings at this time contributing to the mean reading, with work days on the left, and control days away from work on the right. The line below shows the area between curves $(A B C)$ for each 2 -hour time block. The ABC score, which is the mean of each 2 -hourly block, is $139 \mathrm{~L} \cdot \mathrm{min}^{-1} \cdot \mathrm{h}^{-1}$. The individual time-points on workdays which are below the $95 \% \mathrm{Cl}$ for rest days are ringed (seven positive time-points). The plot shows a fall in mean $\mathrm{PEF}$ at the first time-point at work and improvement at the first time-point away from exposure.

between rest and work days was in the first 2-hourly time block. For those working more than one shift pattern, morning shifts were used for the analysis. Records with split assessments were resolved in a joint meeting when all records available for an individual worker were compared. The patterns of reaction during SIC and at work were compared using Chi-squared tests. 


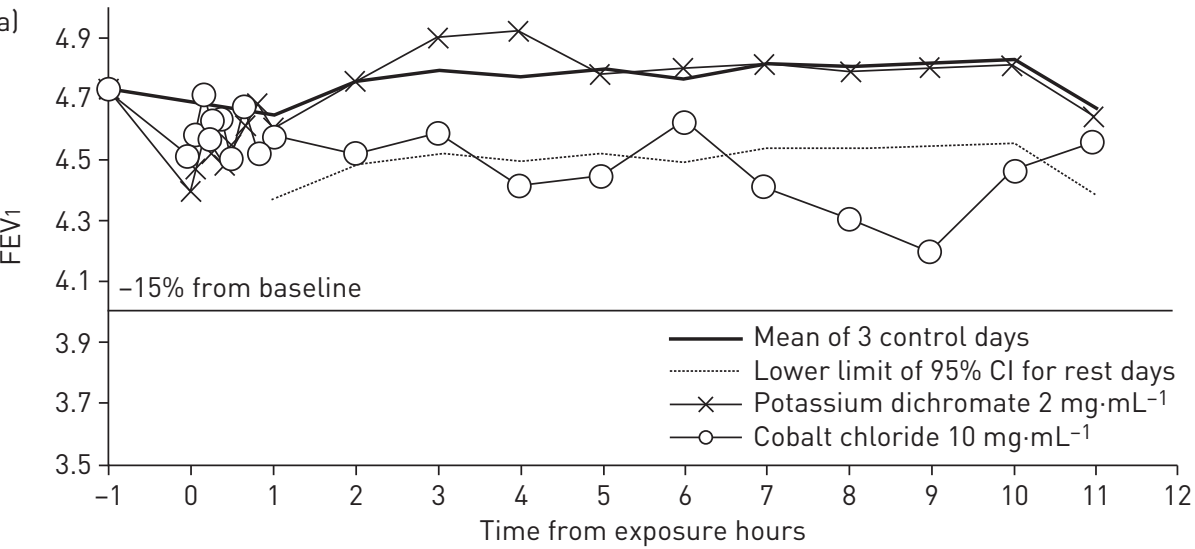

b)

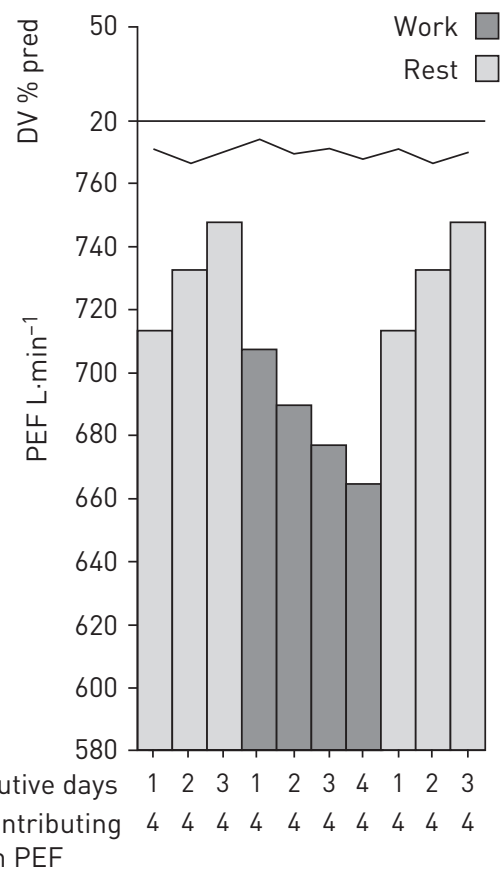

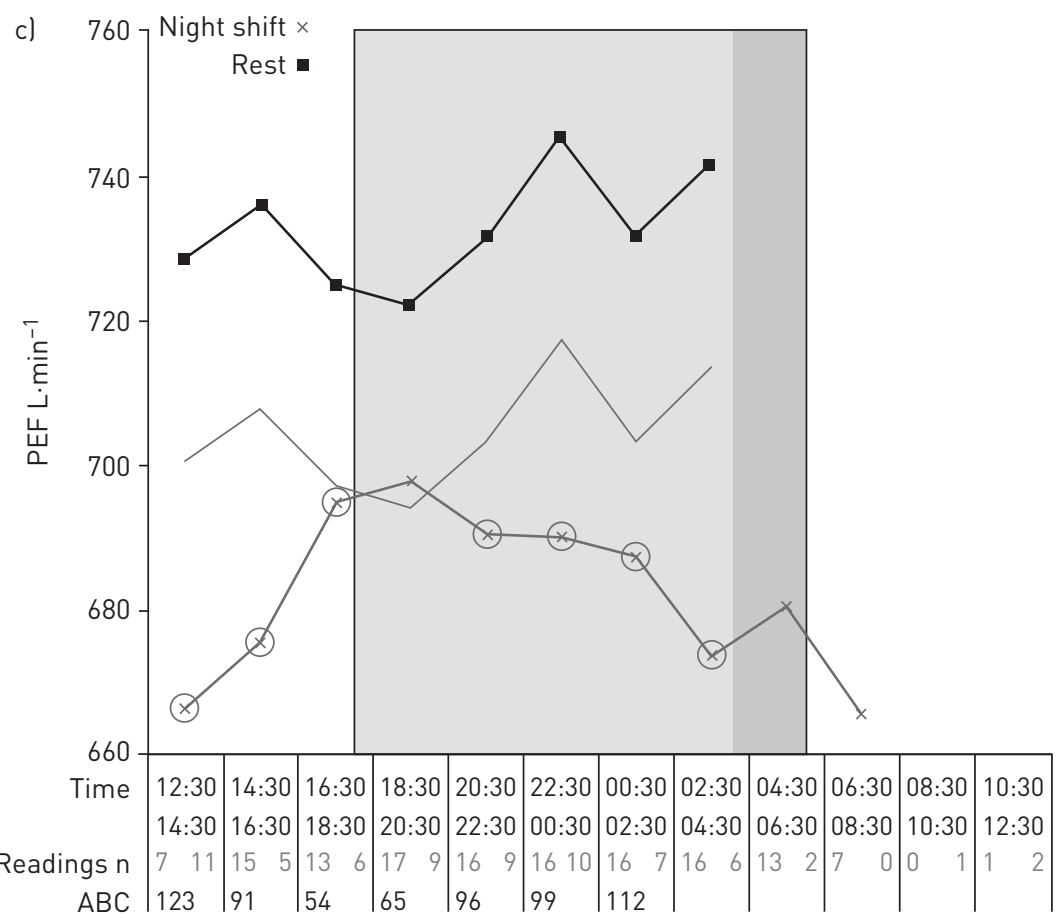

FIGURE 2 Data from a grinder of high cobalt and chrome alloys lubricated with metal working fluid containing dissolved metals from the grinding. a) Specific inhalation test shows the mean hourly peak expiratory flow (PEF) during three rest days away from exposure immediately preceding the challenge tests, the pooled lower limit of the $95 \% \mathrm{Cl}$ for these readings, and responses to two specific challenges on separate days. The specific challenge test shows no reaction to potassium dichromate but a significant late reaction to cobalt chloride with six time-points below the $95 \% \mathrm{Cl}$ for unexposed days. Although the maximum fall in $\mathrm{FEV}_{1}$ is $<15 \%$, the reaction is statistically (and clinically) significant because of the consistency of readings on the three control days [15]. b) Mean PEF on successive days away from exposure and at work. The top panel shows the mean diurnal variation (DV) for each day as a percentage of the predicted value. The main panel shows the mean PEF for each successive control or work day. The top row of the bottom panel numbers the first, second and third consecutive control day away from work either side of days 1-4 at work. The bottom row of the bottom panel indicates the number of days contributing to each mean daily PEF. The plot shows progressive deterioration with each work day and recovery increasing for at least 3 days away from exposure. c) Mean 2-hourly PEF on control days away from work (with $95 \% \mathrm{Cl}$ parallel below) and workdays. Grey background indicates periods at work. Vertical lines indicate the modal times of starting work $(18: 00 \mathrm{~h})$ and leaving work $(06: 00 \mathrm{~h})$. Dark grey indicates the earliest time of leaving work (04:00 h). The first two lines in the bottom panel show the times in 2-hourly blocks; below this are the number of days with readings at this time contributing to the mean reading, with work days on the left and control days away from work on the right. For control days away from work there were fewer than three measurements in the time-block 04:30-06:30 h, so the minimum requirements were not met and no value is plotted. The line below shows the area between curves (ABC) for each 2-hour time block. The ABC score, which is the mean of each 2-hourly block, is $46 \mathrm{~L} \cdot \mathrm{min}^{-1} \cdot \mathrm{h}^{-1}$. The individual time-points on workdays which are below the $95 \% \mathrm{Cl}$ for rest days are ringed (seven positive time-points). The start of deterioration on workdays is delayed by at least $4 \mathrm{~h}$, and recovery does not start until waking after sleep.

Methacholine $\mathrm{PC}_{20}$ was measured at the beginning and end of each series of challenges. The method was changed from the Yan technique (in which hyperresponsiveness is classed as $<4800 \mu \mathrm{g}$ ) [16] to a method using the Jaeger dosimeter (in which hyperresponsiveness is classed as <2.8 $\mathrm{mg}$ ) [17]; these are approximately equivalent to $32 \mathrm{mg} \cdot \mathrm{mL}^{-1}$ using usual methods [18]. 


\section{Results}

53 of the 111 workers had a positive SIC and form the cohort for this study. The other 58 workers had negative SICs, with 36 of them having peak flow evidence of occupational asthma. PEF records were returned by 52 of the 53 workers with a positive SIC. One illiterate worker failed to return anything. 14 of the 52 needed more than one attempt to provide adequate records. Records were adequate for assessing the hourly response to work exposure in 50 of the 52; two contained no readings at work. One additional record had no readings on days away from work. The remaining 49 records with adequate recording at and away from work were positive for at least one of the Oasys scores demonstrating a significant occupational effect; 44 of the records were positive for two or more of the scores.

The relationship between the timing of reactions during SIC and in the real-world exposures is shown in table 2. There were nine workers with SIC isolated late reactions. Of these, eight showed a delayed start of deterioration in recordings at work: six showed progressive daily deterioration with each workday exposure and in three of the six recovery took $>1$ day. Seven of the nine had a delayed start of recovery after leaving work (figure 4). One worker exposed to aerosols from a water-based washer of machined metal showed an early flat response and early recovery after work, with maximal reactions at the beginning of the working week and progressive improvement from day 3 onwards, suggesting an endotoxin-type reaction.

There were 20 workers with SIC isolated immediate reactions with no evidence of a late reaction, although one worker's record was insufficient to assess the timings of daily reactions. 15 of the remaining 19 had an early start of deterioration at work and 13 an early start of recovery after leaving work (11 of the 19 had both). Of the 18 workers with consecutive workdays, nine had equivalent deterioration, nine had progressive deterioration on each workday and nine took $>1$ day to recover.

There were 24 workers with dual (immediate and late) SIC reactions. Three had no recordings on workdays and one had unclassifiable patterns of reaction at work. In 12 of the remaining 19, there was a delayed start of deterioration, and in 11 there was a delayed start of recovery after leaving work. Only three workers showed an early start of deterioration at work and a delayed start of recovery. Of the 18 workers with sequential days of work exposure, nine showed progressive day-by-day deterioration at work. 12 of the 19 showed rest day improvement taking $>1$ day.

The type of SIC reaction showed a significant relationship with the speed of onset of PEF decline at work (Chi-squared for start of reaction at work 13.1, $\mathrm{p}=0.0014$ ) and with the time for the PEF to start improving after work (Chi-squared for start of recovery at work 6.9, $\mathrm{p}=0.032$ ). There were no significant differences between the type of challenge reaction and either the response to successive daily exposures or the time to reach a plateau on days away from work.

NSBR was measured within 4 weeks of the last occupational exposure in 18 of the 24 with normal NSBR and 22 of the 29 with hyperresponsiveness. A search for predictors of SIC response showed that immediate SIC reactors had more NSBR (Chi-squared 6.52, $\mathrm{p}=0.03$ ), and had significantly greater falls in FEV1 during the immediate reaction than those with dual reactions $(p=0.002)$ (table 3$)$. Post-SIC NSBR increased more often following dual reactions; the differences (compared with immediate reactors) were not statistically significant (Chi-squared 2.6, $\mathrm{p}=0.27$ ). The late SIC reactors were unusual in that none showed increased NSBR post SIC. Workers with isolated late reactions were less likely to be taking inhaled corticosteroids during SIC (Chi-squared 4.52, $\mathrm{p}=0.012$ ).

\section{Discussion}

There was a good correlation between immediate SIC reactors and deterioration within the first $2 \mathrm{~h}$ of starting work and early recovery, and between late SIC reactors and a delayed start to workplace

TABLE 2 Comparison of timing of asthmatic reactions in the challenge chamber (SIC) and in real-world exposures at work

Laboratory challenge reaction
Subjects $n$

\section{Taking ICS during SIC}

PEF response at work

\begin{tabular}{lccccc}
\cline { 5 - 6 } & \multicolumn{2}{c}{ Start of deterioration } & & \multicolumn{2}{c}{ Start of recovery } \\
\cline { 2 - 3 } \cline { 6 - 6 } & Immediate & Delayed & & Immediate & Delayed \\
\hline $11 / 20$ & $15 / 19$ & $4 / 19$ & & $13 / 19$ & $6 / 19$ \\
$15 / 24$ & $8 / 20$ & $12 / 20$ & & $7 / 19$ & $12 / 19$ \\
$2 / 9$ & $1 / 9$ & $8 / 9$ & & $2 / 8$ & $6 / 8$ \\
\hline
\end{tabular}

Chi-squared for start of reaction at work 13.1 ( $p=0.0014)$. Chi-squared for start of recovery at work 6.9 ( $p=0.032$ ). Chi-squared for use of inhaled corticosteroids during SIC 4.52 ( $p=0.012$ ). ICS: inhaled corticosteroid; SIC: specific inhalation challenge; PEF: peak expiratory flow. 
TABLE 3 Changes in FEV1 and nonspecific bronchial reactivity following SIC

\begin{tabular}{|c|c|c|c|c|}
\hline SIC reaction & Baseline hyper-reactivity & $\begin{array}{l}\text { Increased hyper-reactivity } \\
\text { post SIC }\end{array}$ & $\begin{array}{l}\text { Immediate reaction } \% \text { fall in } \\
\text { FEV } 1 \text { mean } \pm \text { SD }\end{array}$ & $\begin{array}{l}\text { Late reaction } \% \text { fall in } \\
\text { FEV1 mean } \pm \text { sD }\end{array}$ \\
\hline Immediate & $15 / 20^{\#}$ & $6 / 20^{\pi}$ & $32.4 \pm 14.0$ & $8.6 \pm 3.7$ \\
\hline Late & $3 / 9$ & $0 / 9$ & $7.0 \pm 3.3$ & $20.6 \pm 8.2$ \\
\hline
\end{tabular}

SIC: specific inhalation challenge; FEV1: forced expiratory volume in 1s. *: baseline reactivity (three groups) Chi-squared 6.52 (p=0.03);

ๆः change in reactivity post challenge comparing immediate and dual reactors Chi-squared 2.6 ( $p=0.27) ;{ }^{+}$: unpaired two-tailed t-test; immediate reactions comparing immediate and dual reactors $\mathrm{p}=0.002$.

deterioration and delayed recovery. Workers with dual reactions, i.e. immediate followed by late SIC reaction, rarely had deterioration within the first $2 \mathrm{~h}$ of starting work and a delayed recovery after leaving work as we had postulated, with some behaving more like immediate SIC reactors and some more like late reactors. We were able to validate the positive SIC responses to a wide range of unusual agents that mostly act by unknown mechanisms, with regular deterioration following usual work exposures shown in all those with adequate peak flow records.

Real-world occupational asthma involves repeated daily exposure to the causative agent, often over many months or years before a diagnosis is made. There are, however, very few studies investigating the effect of repeated positive daily laboratory challenges. STENTON et al. [15] carried out detailed studies of three workers sensitised to sodium iso-nonanoyl oxybenzene sulfonate with increasing inhaled doses for 8 days during their validation of the lower limit of normal method of detecting significant late asthmatic reactions during SIC testing (the Oasys time-point analysis is modelled on this method) [15]. Although not reported in the paper, repeated exposures resulted in shortening of the interval between exposure and falls in FEV1 (S.C. Stenton, personal communication). It is also possible that repeated daily exposures lead to a degree of tolerance.

Little is known about the mechanisms separating the early from the late SIC reactions. Most studies have been with IgE-mediated reactions in which pre-challenge nonspecific reactivity is greater in dual than immediate reactors, and the magnitude of the immediate reaction is a determinant of the subsequent late reaction [19]. A population similar to ours from Barcelona showed that workers exposed to high molecular weight agents had increased SIC reactions compared to workers exposed to low molecular weight agents, and that bronchial responsiveness pre-SIC was the major determinant of the dose needed to elicit a reaction [20]. In our study with predominantly low molecular weight agents (and only two out of 53 with IgE antibodies to high molecular weight antigens), we found that larger immediate reactions did not predispose to dual reactions; all responses were allowed to resolve spontaneously without extra treatment, removing rescue treatment during SIC as a confounding factor. Single doses of inhaled corticosteroids have been shown to lessen the late but not the immediate SIC response [21]; however, longer-term use of inhaled corticosteroids can inhibit both phases of the reaction [22]. The use of inhaled corticosteroids in this study was less frequent in those with isolated late reactions, but similar in those with immediate or dual reactions. Inhaled corticosteroids may well have lessened the extent of the reactions.

The exposures and lung function monitoring during inpatient SIC testing are carefully controlled, in contrast to the less controlled situation in the workplace. At work, the exposures may vary considerably from one occasion to another and may even be absent on some days. In our study, when the worker identified days with specific exposures (such as welding stainless steel rather than mild steel), the peak flow record analysed was from the exposed days alone. It is, however, likely that some of the variability in timing of reactions at work relates to unrecorded differences in exposures. The method of averaging all measurements in 2-hourly blocks on exposed workdays may have ameliorated some of this variance. There was at least one worker with an immediate SIC and a late start for workplace deterioration whose exposures were largely in the last hour at work each day, when the workplace was being swept. Despite this, there were significant relationships between the patterns of reaction during SIC and in the workplace.

In our study, $47 \%$ of workers had normal baseline NSBR. This is consistent with a systematic review of diagnostic methods for occupational asthma which showed that the pooled results for normal nonspecific bronchial responsiveness was $20.7 \%$ (95\% CI 12.4-32.3) for high molecular weight agents and 33.3\% (95\% CI 23-41.8) for low molecular weight agents [23]. NSBR may return to normal if there is a significant interval between the last exposure to the cause and NSBR measurement. The interval between last occupational exposure and measurement of NSBR was $<4$ weeks in 40 of the 53 workers and showed no 
difference between those with and without NSBR. Our previous series of low molecular weight occupational asthma including induced sputum measurements showed that the eosinophilic phenotype accounted for only $37 \%$ of those with positive SIC, and was associated with greater NSBR, higher levels of expired nitric oxide fraction (FeNO), greater bronchodilator reversibility and worse health-related quality of life [24]. The same was true when workers with occupational asthma were divided into phenotypes based on FeNO [25]. The relatively low level of increased NSBR in this study is likely to be due to a low level of the eosinophilic phenotype.

Self-measurement of lung function at work requires worker cooperation and has been criticised because the effort required to carry out the recordings can result in suboptimal effort while working, or fabrication of results. Some workers do record measurements not captured on data-logging spirometers. 41 workers with suspected occupational asthma kept PEF records on a Vitalograph 2110 electronic meter that, unknown to them, stored the results. A study comparing hand-written and data-logged readings showed that, for $66 \%$ of workers, there was $<10 \%$ difference between hand-written and data-logged readings [26]. Readings that were written but not logged tended to regress to the workers mean: the mean differences were $+4.5 \mathrm{~L} \cdot \mathrm{min}^{-1}$ for workdays and $-6.4 \mathrm{~L} \cdot \mathrm{min}^{-1}$ for days away from work, tending to minimise any work effect. Three workers had Oasys scores from the hand-recorded data that suggested occupational asthma, but these data were not supported by the data-logged readings. In each of these instances, the workers were identified from blind assessment of their records [26]. Suboptimal effort is mitigated to some extent by the quality control embedded in logging spirometers and the instruction to do more readings if the best two are $>20 \mathrm{~L} \cdot \mathrm{min}^{-1}$ apart. Lack of effort at work could only account for those with early recovery after leaving work (58\% did not show early recovery).

We do not think that it is possible to calculate the sensitivity or specificity of serial peak flow analysis from the current data. Specificity requires comparison with a population of patients with asthma of similar severity in whom occupational asthma has been excluded. This has been done using patients with asthma who are not at work by arbitrarily attributing measurements from Monday to Friday as "at work". This provides a specificity of $89 \%$ for any one of the four scores in the Oasys programme, and $93-100 \%$ when two or more of the scores are positive [4]. There are many reasons why a SIC may be negative with genuine occupational asthma, particularly the failure to expose the worker to the causative agent during SIC, making any generalisable estimate of SIC sensitivity problematic. SIC is likely to achieve high sensitivity for the specific antigen tested; however, testing with the specific antigen that the worker is exposed to can be difficult. For instance, modification of antigen binding sites by genetically modifying enzymes in baking can lead to false negative tests with the native enzyme but positive tests with the modified enzyme [27]. From the current data, it is possible to conclude that the criteria for a positive SIC reaction used with the agents tested did not produce false positive results (specificity $100 \%$ ), although others have shown that positive SIC reactions can be induced specifically by using high-enough antigen doses in those with positive IgE to the test agent who have never had any evidence of asthma or rhinitis [28].

In conclusion, there was a good correlation between the timings of response to exposures at work and in the challenge chamber for those with isolated immediate or late reactions. Those with dual SIC reactions did not often have an early start of deterioration at work with a delayed recovery as predicted but fitted more closely into either the immediate or late category.

Conflict of interest: None declared.

References

1 Vandenplas O, Suojalehto H, Aasen TB, et al. Specific inhalation challenge in the diagnosis of occupational asthma: consensus statement. ERS Task Force on Specific Inhalation Challenges with Occupational Agents. Eur Respir J 2014; 43: 1573-1587.

2 Gannon PF, Newton DT, Belcher J, et al. Development Of OASYS-2: a system for the analysis of seria measurement of peak expiratory flow in workers with suspected occupational asthma. Thorax 1996; 51: 484-489.

3 Moore VC, Jaakkola MS, Burge CBSG, et al. A new diagnostic score for occupational asthma. Chest 2009; 135: 307-314.

4 Burge CBSG, Moore VC, Pantin CFA, et al. Diagnosis of occupational asthma from time point differences in serial PEF measurements. Thorax 2009; 64: 1032-1036.

5 Walters GI, Kirkham A, McGrath EE, et al. Twenty years of SHIELD: decreasing incidence of occupational asthma in the West Midlands, UK? Occup Environ Med 2015; 72: 304-310.

6 Pepys J, Hutchcroft BJ. Bronchial provocation tests in etiologic diagnosis and analysis of asthma. Am Rev Respir Dis 1975; 112: 829-859.

7 Newman Taylor AJ, Davies RJ, Hendrick DJ, et al. Recurrent nocturnal asthmatic reactions to bronchial provocation tests. Clin Allergy 1979; 9: 213-219.

8 Baur X, Sigsgaard T, Aasen TB, et al. Guidelines for the management of work-related asthma. Eur Respir J 2012; 39: 529-545. 
9 Hetzel MR, Clark TJH. Comparison of normal and asthmatic circadian rhythms in peak expiratory flow rate Thorax 1980; 35: 732-738.

10 Randem B, Smolensky MH, Hsi B, et al. Field study of circadian rhythm in PEF of electronics workers suffering from colophony-induced asthma. Chronobiol Int 1987; 4: 263-267.

11 Moore VC, Jaakkola MS, Burge CBSG, et al. Shift work effects on serial PEF measurements for occupational asthma. Occup Med 2012; 62: 525-532.

12 Burge PS, O'Brien IM, Harries MG. Peak flow rate records in the diagnosis of occupational asthma due to colophony. Thorax 1979; 34: 308-316.

13 Burge PS, O'Brien IM, Harries MG. Peak flow rate records in the diagnosis of occupational asthma due to isocyanates. Thorax 1979; 34: 317-323.

14 Burge PS. Single and serial measurements of lung function in the diagnosis of occupational asthma. Eur J Respir Dis Suppl 1982; 63: 47-59.

15 Stenton SC, Avery AJ, Walters EH, et al. Statistical approaches to the identification of late asthmatic reactions. Eur Respir J 1994; 7: 806-812.

16 Yan K, Salome CM, Woolcock AJ. Rapid method for measurement of bronchial responsiveness. Thorax 1983; 38: $760-765$.

17 Schulze J, Rosewich M, Riemer C, et al. Methacholine challenge - comparison of an ATS protocol to a new rapid single concentration technique. Respir Med 2009; 103: 1898-1903.

18 Hargreave FE, Ryan G, Thomson NC, et al. Bronchial responsiveness to histamine or methacholine in asthma: measurement and clinical significance. J Allergy Clin Immunol 1981; 68: 347-355.

19 Boulet L-P, Gauvreau G, Boulay M-E, et al. Allergen-induced early and late asthmatic responses to inhaled seasonal and perennial allergens. Clin Exp Allergy 2015; 45: 1647-1653.

$20 \mathrm{Hu} \mathrm{C}$, Cruz M, Ojanguren I, et al. Specific inhalation challenge: the relationship between response, clinical variables and lung function. Occup Environ Med 2017; 74: 586-591.

21 Pepys J, Davies RJ, Breslin ABX, et al. The effects of inhaled beclomethasone dipropionate (Becotide) and sodium cromoglycate on asthmatic reactions to provocation tests. Clin Allergy 1974; 4: 13-24.

22 Burge PS, Efthimiou J, Turner-Warwick M, et al. Double-blind trials of inhaled beclomethasone dipropionate and fluocortin butyl ester in allergen-induced immediate and late asthmatic reactions. Clin Allergy 1982; 12: 523-531.

23 Beach J, Russell K, Blitz S, et al. A systematic review of the diagnosis of occupational asthma. Chest 2007; 131: 569-578.

24 Anees W, Huggins V, Pavord ID, et al. Occupational asthma due to low molecular weight agents: eosinophilic and non-eosinophilic variants. Thorax 2002; 57: 231-236.

25 Moore VC, Anees W, Jaakkola MS, et al. Two variants of occupational asthma separable by exhaled breath nitric oxide level. Respir Med 2010; 104: 873-879.

26 Anees W. The relationship between airways physiology, airways inflammation and prognosis in workers with occupational asthma. PhD thesis, University of Birmingham 2002.

27 Budnik LT, Scheer E, Burge PS, et al. Sensitising effects of genetically modified enzymes used in flavour, fragrance, detergence and pharmaceutical production: cross-sectional study. Occup Environ Med 2017; 74: 39-45.

28 Bryant DH, Burns MW. Bronchial histamine reactivity: its relationship to the reactivity of the bronchi to allergens. Clin Allergy 1976; 6: 523-532. 